\title{
Robot-Assisted Laparoscope Fundoplication for Gastroesophageal Reflux Disease: A Systematic Review of Randomized Controlled Trials
}

\author{
Peng Zhang ${ }^{a, b}$ Jin-Hui Tian ${ }^{a, c}$ Ke-Hu Yang ${ }^{a, b}$ Jun Lia,b Wen-Qin Jia ${ }^{a, c}$ \\ Shao-Liang Sun ${ }^{a, b}$ Bin Maa,c Ya-Li Liuª, \\ ${ }^{a}$ Evidence-Based Medicine Center, ${ }^{\mathrm{b}}$ The First Clinical Medical College, and ${ }^{\mathrm{C} S}$ School of Basic Medical Sciences, \\ Lanzhou University, Lanzhou, China
}

\section{Key Words}

Robotics · Laparoscopy · Fundoplication ·

Gastroesophageal reflux disease

\begin{abstract}
Objective: To evaluate the efficacy and safety of robot-assisted fundoplication (RAF) for treating gastroesophageal reflux disease (GERD). Methods: Randomized controlled trials (RCTs) or quasi-RCTs were searched for in PubMed, EMBASE, the Cochrane Library, SCl, Chinese Biomedical Database, China Academic Journals Full-Text Database, Chinese Scientific Journals Database, China online journals, and related journals. We evaluated the quality of the included studies by using the 5.0.1 Cochrane Handbook standards and analyzed the data using the Cochrane Collaboration's RevMan 5.0. Results: Five studies $(n=181)$ were included. A meta-analysis showed that besides the time taken to carry out fundoplication $(p<0.00001)$, both RAF and conventional laparoscopic fundoplication (CLF) were similar in postoperative antisecretory medication $(p=1.0)$, intraoperative conversion to open surgery $(p=0.94)$, postoperative dysphagia $(p=1.0)$, pneumothorax $(p=1.0)$, total intraoperative complications $(p=0.24)$, the time of hiatal dissection $(p=$ $0.98)$, the time of incision to completion of sutures $(p=0.95)$, total operation time $(p=0.16)$, hospital stay $(p=0.97)$, and total cost $(p=0.25)$. Conclusions: The current evidence dem-
\end{abstract}

onstrates that RAF is safe and effective in treating GERD. The weakness of this treatment method is that it prolongs the time necessary to carry out fundoplication. However, RAF should be the future trend for treating GERD.

Copyright $\odot 2009$ S. Karger AG, Basel

\section{Introduction}

Gastroesophageal reflux disease (GERD) is one of the most common health problems, and it affects more than $50 \%$ of the world's population [1]. Both medical and surgical treatments have shown outstanding results in treating this disease [2]. At present, the routine treatment is the administration of proton pump-inhibiting drugs. Antireflux surgery appears to be an interesting treatment alternative because of the adverse effects and the unwillingness of some patients to be involved in long-term medical therapy. Typically, conventional laparoscopic fundoplication (CLF) is the preferred surgical option. However, as attractive as minimally invasive surgery is, there are several limitations that CLF has as traditional laparoscopy.

First, it is limited by 2-dimensional imaging and restricted instrument motion, and it leads to ocular fatigue, headaches, and nausea in surgeons [3-6]. Second, haptic feedback (force and tactile), natural hand-eye coordina-

\section{KARGER}

Fax +4161306 1234 E-Mail karger@karger.ch www.karger.com
(C) 2009 S. Karger AG, Basel

0012-2823/10/0811-0001\$26.00/0

Accessible online at:

www.karger.com/dig
Ke-Hu Yang

Evidence-Based Medicine Center

Lanzhou University

Lanzhou 730000 (China)

Tel. +86931 891 2767, Fax +86931891 5076, E-Mail kehuyangebm2006@126.com 
tion, and dexterity are not necessary. Third, physiologic tremors of the surgeon are readily transmitted through the length of rigid instruments. These limitations make more delicate dissections and anastomoses difficult [7].

During the last few years, 'experimental approach' minimally invasive robot-assisted surgery has continued to expand into more and more realms of surgery. The motivation to develop surgical robots is rooted in the desire to overcome the limitations of current laparoscopic technologies and to expand the benefits of minimally invasive robot-assisted surgery. For example, the benefits include three-dimensional images, which allow surgeons to operate with superior visibility; furthermore, the robotic system has a $360^{\circ}$ range of motion, maintains steadiness, and uses more sophisticated surgical tools with greater degrees of freedom [8]. Since the first report of robot-assisted fundoplication (RAF) published in 1997, computer-assisted fundoplication has become increasingly popular. Consequently, more authors have reported their experience with these devices in antireflux surgery [9]. But controversy remains regarding the preferred surgical technique for the treatment of GERD.

Current studies show that some people think that RAF has emerged as a promising technical innovation $[10,11]$. On the other hand, others say it adds to the operation time and increases the cost [12-15]. The tangible benefits of integrating robotics into surgical fundoplication practice remain unclear. To explore this issue, we use the method of the Cochrane systematic review to conduct a comprehensive evaluation of the relevant trials in order to provide the best clinical evidence.

\section{Methods}

Search Strategy and Selection Criteria

We searched PubMed (1966 to Nov. 2008), EMBASE (1974 to Nov. 2008), the Cochrane Library (issue 4, 2008), SCI (1974 to Nov. 2008), Chinese Biomedical Database (1978 to Nov 2008), China Academic Journals Full-Text Database (1994 to Nov. 2008), Chinese Scientific Journals Database (1989 to Nov. 2008), and China Online Journals (1997 to Nov. 2008) for English language articles using the format: '(telerobotics OR remote operation* OR robot $^{*}$ ) AND (laparoscopi* OR peritoneoscop ${ }^{*}$ OR celioscop ${ }^{*}$ OR laparoscopic surgical procedure* OR laparoscopic surger*) AND (fundoplication OR nissen operation OR gastroesophageal reflux disease OR gastro esophageal reflux OR gastro oesophageal reflux OR GER*')' We also searched some journals that are devoted to laparoscopy and GERD. In addition, we contacted investigators and experts for ongoing and unpublished studies, and scanned references listed in primary studies, review articles, and textbook chapters.
Searches were conducted independently by Dr. Zhang and Dr. Tian. Reference lists from all relevant articles were reviewed to identify additional studies, and the final bibliography was distributed to experts in the field to identify missing or unpublished studies.

We included all randomized controlled trials (RCTs) or quasiRCTs if they described using RAF versus CLF for the treatment of GERD and reported the surgical complications, operation time, total cost, duration of hospital stay, and other relevant information. All the participants in this study suffered from operable pathologic gastroesophageal reflux which was documented by stereoscopy, 24-hour $\mathrm{pH}$ measurements, barium swallow, and esophageal manometry. Studies without raw data available for retrieval and a clearly defined type of dissection were excluded.

\section{Quality Assessment and Data Extraction}

The methodological quality of each study was assessed by Dr. Tian and Dr. Sun, using adapted criteria from the Cochrane Handbook version 5.0.1 from the Cochrane Collaboration guidelines [16]. Two reviewers (Dr. Tian and Dr. Li) independently assessed these trials for eligibility and extracted data. Disagreement was solved by discussions with Dr. Yang.

We acquired additional information by interviewing the original authors via telephone. Data was obtained from authors, institutions, study design, patient characteristics, date of publication, and technical features of the studies.

\section{Statistical Analysis}

Meta-analyses were carried out by using Review Manager Software (RevMan, version 5.0) provided by the Cochrane Collaboration [17]. If there was no statistically significant heterogeneity in a given set of data, the fixed effects model was used for meta-analysis. If the results of trials showed heterogeneity, the random effects model was used. Statistical heterogeneity between studies was evaluated using the $\chi^{2}$ test and the $\mathrm{I}^{2}$ statistic. Potential causes of heterogeneity were explored by carrying out sensitivity and subgroup analyses. Results were expressed as relative risk or mean difference with $95 \%$ confidence intervals (CI). p $<$ 0.05 was considered statistically significant.

\section{Results}

A total of 130 studies were identified using the abovementioned search strategy, and 125 articles which did not meet the inclusion criteria were subsequently excluded. The baselines of each trial were comparable. Figure 1 details the selection process. A total of 5 studies were included [11-15]. Table 1 shows the characteristics of the studies included in this systematic review. Table 2 includes the quality assessment of studies.

\section{Primary Analysis}

Surgical Complications

The fixed effects model was used because there was no heterogeneity in these data sets: postoperative antisecre- 
PubMed $(n=8)$

EMBASE $(n=40)$

$\mathrm{SCl}(\mathrm{n}=51)$

Cochrane Library $(n=13)$

Wanfang Database $(n=6)$

Chinese Biomedical Literature Database $(n=1)$

China Journal Full-Text Database $(n=11)$

Chinese Scientific Journals Full-Text Database $(n=0)$

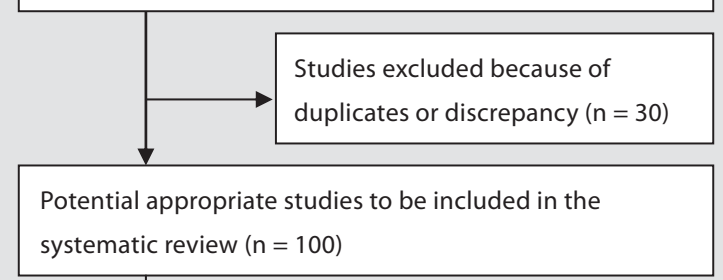

systematic review $(n=100)$

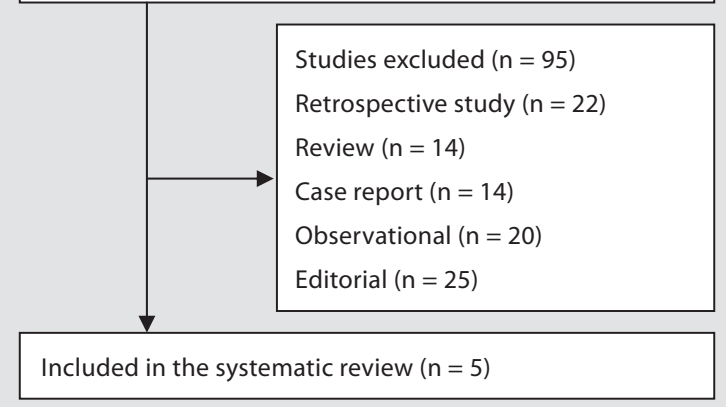

Fig. 1. Selection of study.

tory medication $\left(\mathrm{I}^{2}=0 \%, \mathrm{p}=0.45\right)$, intraoperative conversion to open surgery $\left(\mathrm{I}^{2}=13 \%, \mathrm{p}=0.32\right)$, postoperative dysphagia $\left(\mathrm{I}^{2}=0 \%, \mathrm{p}=0.78\right)$, pneumothorax $\left(\mathrm{I}^{2}=0 \%\right.$, $\mathrm{p}=0.33)$, and total intraoperative complications $\left(\mathrm{I}^{2}=0 \%\right.$, $\mathrm{p}=0.82$ ). The results showed that there were no significant differences in postoperative antisecretory medication $(\mathrm{OR}=1.0,95 \% \mathrm{CI}: 0.23,4.29 ; \mathrm{p}=1.0)$, intraoperative conversion to open surgery $(\mathrm{OR}=1.05,95 \% \mathrm{CI}$ : $0.23,4.74$; $\mathrm{p}=0.94)$, postoperative dysphagia $(\mathrm{OR}=1.0,95 \% \mathrm{CI}$ : $0.36,2.74 ; \mathrm{p}=1.0)$, pneumothorax $(\mathrm{OR}=1.0,95 \% \mathrm{CI}: 0.14$, $7.33 ; \mathrm{p}=1.0)$, and total intraoperative complications $(\mathrm{OR}=0.49,95 \% \mathrm{CI}: 0.15,1.62 ; \mathrm{p}=0.24)$ between $\mathrm{RAF}$ and CLF (fig. 2).

\section{Operation Times}

Figure 3 shows the data for the time necessary to carry out fundoplication $\left(\mathrm{I}^{2}=24 \%, \mathrm{p}=0.25\right)$ for RAF and CLF, respectively. Two studies $[12,15]$ were included. The result showed that RAF prolonged the time necessary to carry out fundoplication [weighted mean difference $(\mathrm{WMD})=3.17,95 \%$ CI: $2.33,4.00 ; \mathrm{p}<0.00001]$.

Figures 4-6 show that the data for the time needed for hiatal dissection $\left(\mathrm{I}^{2}=82 \%, \mathrm{p}=0.02\right)$, the time from incision to completion of sutures ( $\left.\mathrm{I}^{2}=95 \%, \mathrm{p}<0.0001\right)$, and the total operation time $\left(\mathrm{I}^{2}=97 \%, \mathrm{p}<0.00001\right)$ exhibited heterogeneity. For this reason the random effects model was used. The results showed that there were no significant differences in the time needed for hiatal dissection (WMD $=-0.10,95 \%$ CI: $-7.25,7.09 ; \mathrm{p}=0.98$ ), the time from incision to completion of sutures (WMD $=-1.04$, 95\% CI: $-31.31,29.82 ; \mathrm{p}=0.95$ ), and total operation time $(\mathrm{WMD}=22.65,95 \% \mathrm{CI}:-8.68,53.99 ; \mathrm{p}=0.16)$ between RAF and CLF.

\section{Hospital Stay}

Figure 7 shows that the data for duration of hospital stay exhibited heterogeneity $\left(\mathrm{I}^{2}=84 \%, \mathrm{p}=0.01\right)$; thus the random effects model was used. The results (WMD = $-0.01,95 \%$ CI: $-0.70,0.67 ; \mathrm{p}=0.97$ ) showed there was no significant difference between RAF and CLF.

\section{Total Cost}

Figure 8 shows that the data for total cost were heterogeneous ( $\left.\mathrm{I}^{2}=96 \%, \mathrm{p}<0.00001\right)$; thus, the random effects model was used. The results (standardized mean difference $=6.39,95 \%$ CI: $-4.61,17.39 ; \mathrm{p}=0.25$ ) showed that there was no significant difference.

\section{Discussion}

This systematic review has demonstrated the apparent feasibility of the robotic procedure. The pooled results of the 5 RCTs showed that no differences were demonstrated between patients who had RAF and CLF regarding surgical complications, time needed for hiatal dissection, time from incision to completion of sutures, total operation time, hospital stay, and total cost. But at the same time, there seem to be some disadvantages, such as prolongation of fundoplication.

Robot-assisted laparoscopic surgery is one of the latest approaches in the evolution of endoscopic surgery. RAF in patients with GERD has been a controversial issue for many years, and several studies have also shown the feasibility and safety of RAF [18-28]. Surgical complications would be the most important outcome of our review. However, there was no clinically significant difference between the surgeries. The reason for this is probably that 
Table 1. Basic information of the studies

\begin{tabular}{|c|c|c|c|c|c|c|c|c|c|}
\hline \multirow[t]{2}{*}{ Study } & \multicolumn{2}{|c|}{ Body mass index } & \multicolumn{2}{|c|}{ Cases } & \multicolumn{2}{|c|}{ Age, years } & \multicolumn{2}{|c|}{ Sex (male/female) } & \multirow[t]{2}{*}{ Outcomes } \\
\hline & RAF & CLF & RAF & CLF & RAF & CLF & RAF & CLF & \\
\hline $\begin{array}{l}\text { Müller-Stich } \\
\text { et al. [11], } 2007\end{array}$ & $\begin{array}{l}29.2 \\
(5.83)\end{array}$ & $\begin{array}{l}26.2 \\
(3.4)\end{array}$ & 20 & 20 & $\begin{array}{l}49.6 \\
(12.0)\end{array}$ & $\begin{array}{l}50.5 \\
(12.4)\end{array}$ & $10 / 10$ & $12 / 8$ & $\begin{array}{l}\text { operation time, operation costs, } \\
\text { complications, hospital stay }\end{array}$ \\
\hline $\begin{array}{l}\text { Morino et al. } \\
{[12], 2006}\end{array}$ & $\begin{array}{l}25.5 \\
(2.9)\end{array}$ & $\begin{array}{l}26.1 \\
(2.3)\end{array}$ & 25 & 25 & $\begin{array}{l}43.0 \\
(12.8)\end{array}$ & $\begin{array}{l}46.3 \\
(11.3)\end{array}$ & $16 / 9$ & $17 / 8$ & $\begin{array}{l}\text { operation time and costs, compli- } \\
\text { cations, postoperative } 24 \text {-hour } \mathrm{pH}\end{array}$ \\
\hline $\begin{array}{l}\text { Draaisma et al. } \\
{[13], 2006}\end{array}$ & $\begin{array}{l}25.6 \\
(19.1-37.2)\end{array}$ & $\begin{array}{l}28.7 \\
(19.5-46.6)\end{array}$ & 25 & 25 & $\begin{array}{l}48.0 \\
(20-74)\end{array}$ & $\begin{array}{l}52.0 \\
(27-71)\end{array}$ & $16 / 9$ & $17 / 8$ & $\begin{array}{l}\text { operation time, blood loss, } \\
\text { complications, hospital stay }\end{array}$ \\
\hline $\begin{array}{l}\text { Cadière et al. } \\
{[14], 2001}\end{array}$ & & & 10 & 11 & $\begin{array}{l}40 \\
(29-62)\end{array}$ & $\begin{array}{l}38 \\
(18-52)\end{array}$ & $7 / 3$ & $8 / 3$ & $\begin{array}{l}\text { operation time, blood loss, } \\
\text { complications }\end{array}$ \\
\hline $\begin{array}{l}\text { Nakadi et al. } \\
{[15], 2006}\end{array}$ & $\begin{array}{l}25.3 \\
(1.2)\end{array}$ & $\begin{array}{l}24.8 \\
(0.7)\end{array}$ & 9 & 11 & $\begin{array}{l}44 \\
(4)\end{array}$ & $\begin{array}{l}48 \\
(4)\end{array}$ & $6 / 3$ & $8 / 3$ & $\begin{array}{l}\text { length of stay, operation time, } \\
\text { operation costs }\end{array}$ \\
\hline
\end{tabular}

Table 2. Methodological quality of included studies

\begin{tabular}{|c|c|c|c|c|c|c|}
\hline \multirow[t]{2}{*}{ Study } & \multicolumn{6}{|c|}{ Assessing risk of bias } \\
\hline & $\begin{array}{l}\text { sequence } \\
\text { generation }\end{array}$ & $\begin{array}{l}\text { allocation } \\
\text { concealment }\end{array}$ & blinding & $\begin{array}{l}\text { incomplete } \\
\text { outcome data }\end{array}$ & $\begin{array}{l}\text { selective out- } \\
\text { come reporting }\end{array}$ & $\begin{array}{l}\text { other potential } \\
\text { threats to validity }\end{array}$ \\
\hline Müller-Stich et al. [11], 2007 & unclear & unclear & single blind & yes & yes & unclear \\
\hline Morino et al. [12], 2006 & random numbers & sealed opaque envelopes & unclear & yes & yes & unclear \\
\hline Draaisma et al. [13], 2006 & unclear & unclear & unclear & yes & yes & unclear \\
\hline Cadière et al. [14], 2001 & unclear & unclear & no & yes & yes & unclear \\
\hline Nakadi et al. [15], 2006 & envelopes & sealed opaque envelopes & no & yes & yes & unclear \\
\hline
\end{tabular}

RAF has only been used a few times. Therefore, it is necessary to study this surgical method further.

All sorts of studies have been published about robotassisted abdominal surgery including cholecystectomy [29], adrenalectomy [30], fundoplication [12-15, 31], and colonic resection [32]. They all have reported that operating time was prolonged. In our study, the prolonged fundoplication time, as indicated by meta-analysis, may be due to the unadapted length of ports in obese patients, inefficient placement of ports, camera motion interrupting the operative procedure, and the unadapted optical system with an absence of a large general view of the operative field, which prevents a safe continuous dissection and necessitates slow manipulation. Also, the technology used by different doctors was not always exactly the same.
The heterogeneity of the data for the time needed for hiatal dissection, the time from incision to completion of sutures, and total operation time may be caused by a lack of familiarity with the technology. The heterogeneity of the data for the length of the hospital stay could be due to different standards for discharge at different hospitals. Every study [11-15] reported that RAF increased total cost compared with CLF, but the results showed that there was no significant difference between the two groups. The heterogeneity of the data of total cost could be caused by different commodity prices. Higher operation cost can be due to the greater expense and consumption of operating room resources such as space and the availability of skilled technical staff, and expensive semidisposable instruments, which can only be used for a predefined number of procedures. 


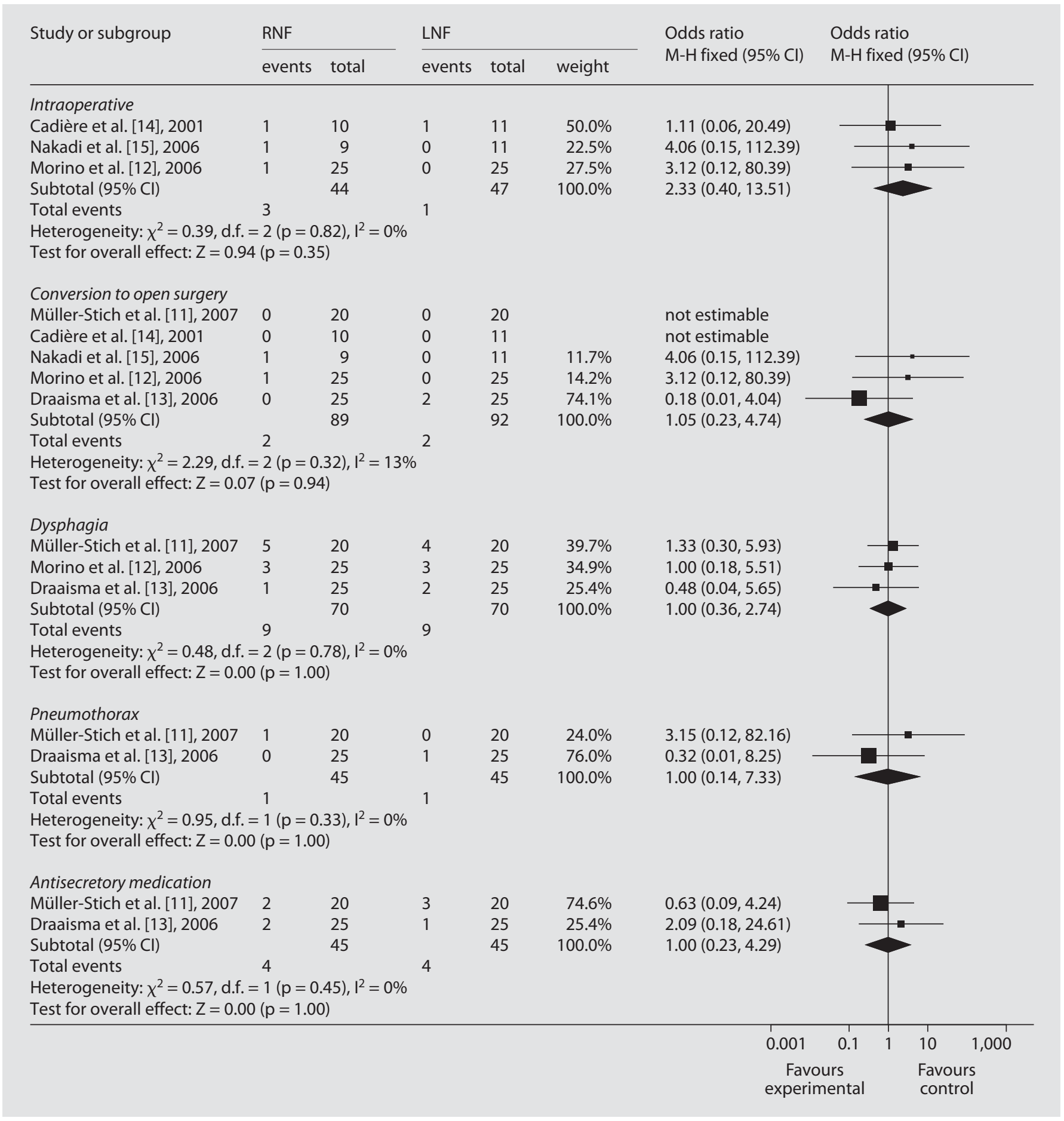

Fig. 2. Surgical complications (person). RNF = Robotic-assisted Nissen fundoplication; LNF = laparoscopic Nissen fundoplication; $\mathrm{M}-\mathrm{H}=$ Mantel-Haenszel. 


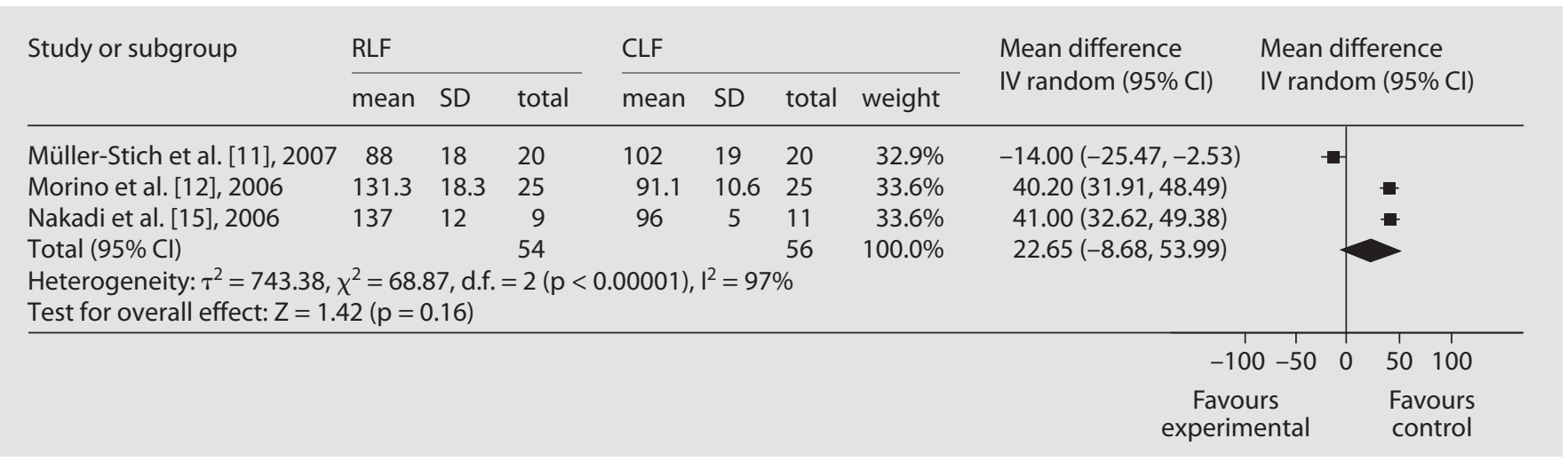

Fig. 6. Total operation time (minute). Abbreviations explained in legends to figures 2 and 3.

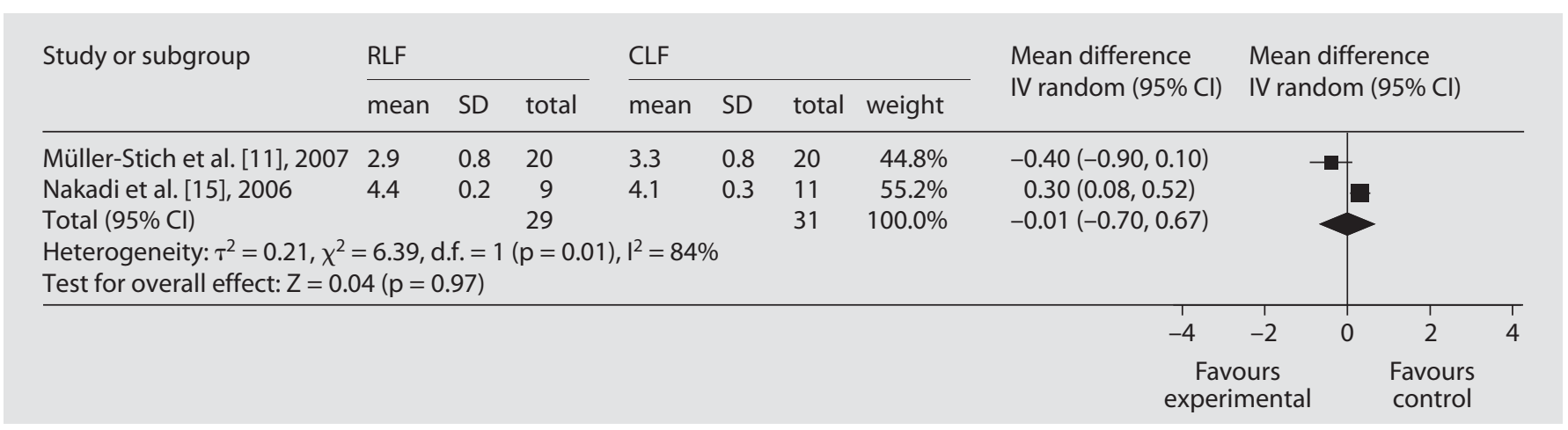

Fig. 7. Hospital stay (day). Abbreviations explained in legends to figures 2 and 3.

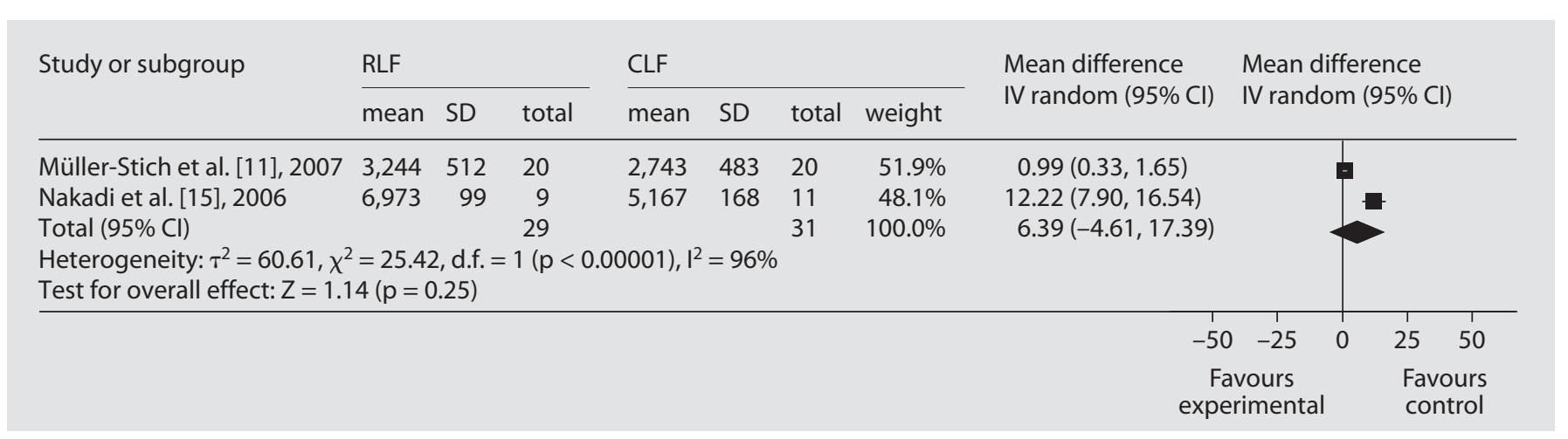

Fig. 8. Total cost (Euro). Abbreviations explained in legends to figures 2 and 3.

mand system, a wider field of vision, specially adapted tools for digestive surgery, tactile sensitivity, and force feedback [33], the operation times will most likely be decreased, and also, the operation costs may decrease with a reduction in the price of materials. As familiarity with the surgery and advances in technology related to the surgery increases, surgical complications will also be reduced.

Postoperative 24-hour $\mathrm{pH}$ values, postoperative selfrated change in reflux symptoms, and quality of life 
should be important, but they all must be independently reported and evaluated. Only Morino et al. [12] reported that postoperative 24 -hour $\mathrm{pH}$ values were normalized in all patients, and that there were no significant differences between the 2 groups. Only Draaisma et al. [13] reported postoperative self-rated change in reflux symptoms, and that quality of life improved equally in both groups.

Our review has several limitations. First, the quality of primary studies determines the quality of such reviews, and the studies included in this systematic review had shortcomings in their methodology. Two $[12,15]$ of the 5 studies included offered adequate descriptions of the randomization process, whereas the other 3 studies $[11,13$, 14] failed to describe the method of allocation satisfactorily. Moreover, allocation concealment was specified only in 2 studies $[12,15]$, and blinding of the outcome assessor was used in only 1 study [11]. This points to possible selection bias and performance bias. In addition, between individual studies, median follow-up and follow-up sequences varied significantly. This incomplete report on follow-up sequences might produce a performance bias. Intention to treat was not used in any trial. Second, because of a shortage of data included in this systematic review, there may be a lack of statistical significance, an appearance of partial bias, and clinical heterogeneity which may distort our results. Third, a lack of standard commodity prices could result in clinical heterogeneity in terms of price. In addition, the primary emphasis of our review was to provide a short-term outcome to elucidate the value of robotic assistance. Therefore, further trials that focus on long-term outcomes are needed to find potential advantages or disadvantages.

\section{Conclusions}

Our study has demonstrated that RAF is safe and effective for treating GERD, but it prolongs the fundoplication time. However, RAF should be the future trend for treatment of GERD. The studies included in this review are limited; therefore, well-designed, large-scale, highquality RCTs (following the CONSORT criteria) are needed.

\section{Acknowledgments}

Ge Zhang, Andrew Bushnell, and Jing Tian provided technical help and writing assistance.

\section{References}

1 Darling G, Deschamps C: Technical controversies in fundoplication surgery. Thorac Surg Clin 2005; 15:437-444.

-2 Stefanidis D, Korndorffer JR, Scott DJ: Robotic laparoscopic fundoplication. Curr Treat Options Gastroenterol 2005;8:71-83.

3 Cheah WK, Lenzi JE, So J, Dong F, Kum CK, Goh P: Evaluation of a head-mounted display (HMD) in the performance of a simulated laparoscopic task. Surg Endosc 2001; 15:990-991.

4 Johns DB, Brewer JD, Soper NJ: The influence of three-dimensional video systems on laparoscopic task performance. Surg Laparosc Endosc 1996;6:191-197.

5 Peli E: The visual effects of head-mounted display (HMD) are not distinguishable from those of desk-top computer display. Vision Res 1998;38:2053-2066.

-6 Tyrrell RA, Leibowitz HW: The relation of vergence effort to reports of visual fatigue following prolonged near work. Hum Factors 1990;32:341-357.

-7 Prasad SM, Ducko CT, Stephenson ER, Chambers CE, Damiano RJ Jr: Prospective clinical trial of robotically assisted endoscopic coronary grafting with 1 year followup. Ann Surg 2001;233:725-732.
8 Eichel L, Ahlering TE, Clayman RV: Role of robotics in laparoscopic urologic surgery. Urol Clin North Am 2004;31:781-792.

-9 Wright AS, Gould JC, Melvin WS: Computer-assisted robotic antireflux surgery. $\mathrm{Mi}$ nerva Gastroenterol Dietol 2004;50:253260.

10 Wykypiel H, Bodner J, Wetscher G, Schmid T: Robot-assisted versus conventional laparoscopic fundoplication: short-term outcome of a pilot randomized controlled study. Surg Endosc 2008;22:1407.

11 Müller-Stich BP, Reiter MA, Wente MN Bintintan VV, Köninger J, Büchler MW, Gutt $\mathrm{CN}$ : Robot-assisted versus conventional laparoscopic fundoplication: short-term outcome of a pilot randomized controlled trial. Surg Endosc 2007;21:1800-1805.

12 Morino M, Pellegrino L, Giaccone C, Garrone C, Rebecchi F: Randomized clinical trial of robot-assisted versus laparoscopic Nissen fundoplication. Br J Surg 2006;93: 553-558.
13 Draaisma WA, Ruurda JP, Scheffer RC, Simmermacher RK, Gooszen HG, Rijnhart-de Jong HG, Buskens E, Broeders IA: Randomized clinical trial of standard laparoscopic versus robot-assisted laparoscopic Nissen fundoplication for gastro-oesophageal reflux disease. Br J Surg 2006;93:1351-1359.

14 Cadière GB, Himpens J, Ertruyen M, Bruyns J, Germay O, Leman G, Izizaw R: Evaluation of telesurgical (robotic) NISSEN fundoplication. Surg Endosc 2001;15:918-923.

-15 Nakadi IE, Mélot C, Closset J, DeMoor V, Bétroune K, Feron P, Lingier P, Gelin M: Evaluation of da Vinci Nissen fundoplication clinical results and cost minimization. World J Surg 2006;30:1050-1054.

16 Higgins JPT, Green S: Cochrane Handbook for Systematic Reviews of Interventions Version 5.0.1 (updated September 2008). The Cochrane Collaboration, 2008. www.cochrane-handbook.org.

17 Review Manager (RevMan) (Computer Program). Version 5.0. Copenhagen, The Nordic Cochrane Centre, The Cochrane Collaboration, 2008. 
18 Chitwood WR Jr, Nifong LW, Chapman WH, Felger JE, Bailey BM, Ballint T, Mendleson KG, Kim VB, Young JA, Albrecht RA: Robotic surgical training in an academic institution. Ann Surg 2001;234:475-484.

-19 Talamini M, Campbell K, Stanfield C: Robotic gastrointestinal surgery: early experience and system description. J Laparoendosc Adv Surg Tech A 2002;12:225-232.

-20 Wykypiel H, Wetscher GJ, Klaus A, Schmid T, Gadenstaetter M, Bodner J, Bodner E: Robot-assisted laparoscopic partial posterior fundoplication with the DaVinci system: initial experiences and technical aspects. Langenbecks Arch Surg 2003;387:411-416.

-21 Melvin WS, Needleman BJ, Krause KR, Schneider C, Wolf RK, Michler RE, Ellison EC: Computer enhanced robotic telesurgery. Initial experience in foregut surgery. Surg Endosc 2002;16:1790-1792.

-22 Talamini MA, Chapman S, Horgan S, Melvin WS: The Academic Robotics Group. A prospective analysis of 211 robotic-assisted surgical procedures. Surg Endosc 2003;17: 1521-1524.
23 Hashizume M, Shimada M, Tomikawa M, Ikeda Y, Takahashi I, Abe R, Koga F, Gotoh N, Konishi K, Maehara S, Sugimachi K: Early experiences of endoscopic procedures in general surgery assisted by a computer-enhanced surgical system. Surg Endosc 2002; 16:1187-1191.

24 Benincà G, Garrone C, Rebecchi F, Giaccone C, Morino M: Robot-assisted laparoscopic surgery. Preliminary results at our center. Chir Ital 2003;55:321-331.

25 Gutt CN, Markus B, Kim ZG, Meininger D, Brinkmann L, Heller K: Early experiences of robotic surgery in children. Surg Endosc 2002; 16:1083-1086.

26 Knight CG, Lorincz A, Gidell KM, Lelli J, Klein MD, Langenburg SE: Computer-assisted robot-enhanced laparoscopic fundoplication in children. J Pediatr Surg 2004;39: 864-866.

27 Corcione F, Esposito C, Cuccurullo D, Settembre A, Miranda N, Amato F, Pirozzi F, Caiazzo P: Advantages and limits of robotassisted laparoscopic surgery: preliminary experience. Surg Endosc 2005;19:117-119.

28 Hanisch E, Markus B, Gutt C, Schmandra TC, Encke A: Robot-assisted laparoscopic cholecystectomy and fundoplication. Initia experiences with the Da Vinci system. Chirurg 2001;72:286-288.
29 Nio D, Bemelman WA, Busch OR, Vrouenraets $\mathrm{BC}$, Gouma DJ: Robot-assisted laparoscopic cholecystectomy versus conventional laparoscopic cholecystectomy: a comparative study. Surg Endosc 2004;18:379-382.

30 Morino M, Benincà G, Giraudo G, Del Genio GM, Rebecchi F, Garrone C: Robot-assisted versus laparoscopic adrenalectomy: a prospective randomized controlled trial. Surg Endosc 2004;18:1742-1746.

-31 Melvin WS, Needleman BJ, Krause KR, Schneider C, Ellison EC: Computer-enhanced versus standard laparoscopic antireflux surgery. J Gastrointest Surg 2002;6:1115.

32 Weber PA, Merola S, Wasielewski A, Ballantyne GH: Telerobotic-assisted laparoscopic right and sigmoid colectomies for benign disease. Dis Colon Rectum 2002;45:16891694.

33 Urban V, Wapler M, Weisener T, Schönmayr R: A tactile feedback hexapod operating robot for endoscopic procedures. Neurol Res 1996;21:28-30. 